- The audit revealed that after attending short training courses dentists are able to provide acupuncture therapy as part of managing patients in primary care.

- Use of this facility may allow anxious patients refusing dental care to obtain dental treatment without resorting to sedation.

- No traumatic complications were reported.

- Provision of training in acupuncture may be included as part of continuing professional development.

\title{
A survey on the uses of acupuncture by a group of UK dentists
}

\author{
P. Rosted ${ }^{1}$ and S. Warnakulasuriya ${ }^{2}$
}

\begin{abstract}
A small number of fully trained Chinese doctors practise Traditional Chinese Medicine (TCM) in western cities. Use of these services by British citizens is extremely limited, mostly due to lack of any knowledge on the effectiveness of acupuncture or exposure to complementary medicine in this country. Common situations where British patients seek the help of TCM are when medical therapy has failed; in relapsing chronic diseases like asthma, rheumatoid arthritis; and in pain management (mostly headache, migraine and back pain). Patients often appreciate that only limited interventions are available for treatment of these conditions in western medicine. At least one in $10 \mathrm{UK}$ specialist physicians are actively involved in complementary and alternative medicine treatments. ${ }^{1}$ A large number of westerners offer acupuncture therapy but lack basic medical training. It is likely that people are reluctant to use these services largely because of hygiene and safety reasons. Moreover, it has been demonstrated that the serious side effects reported are five times more frequent when treatments are provided by non-medically trained therapists compared with professionally registered health care providers. ${ }^{2}$
\end{abstract}

A small number of medical practitioners who have received some higher training in the scientific method and delivery of acupuncture now offer the treatment for a variety of specific medical conditions. In providing this scientific training of acupuncture the points are selected according to writings in traditional Chinese medicine but not according to Chinese tradition or philosophy. The Chinese model is based on the hypothesis that a force of energy (Qi) is circulating in the body in some channels or meridians. If the energy is able to flow freely in the body, the patient is healthy and without pain. If, for various reasons, a blockage of this flow occurs, the patient will be ill and/or in pain. By inserting acupuncture needles in various well defined points, it is possible to restore this free flow

\footnotetext{
${ }_{1 "}$ Pain clinic, Western Park Hospital and Department of Oncology, University of Sheffield, Whitham Road, Sheffield, S10 SJ; ${ }^{2}$ Department of Oral Medicine \& Pathology, Guy's, King's and St Thomas' School of Dentistry, King's College London, Denmark Hill, Caldecot Rd, London SE5 9RW.*Correspondence to Dr P. Rosted Email:prosted@aol.com
}

\section{Refereed Paper}

Received 30.04.03; Accepted 21.01.04

DOI: $10.1038 /$ sj.bdj.4812039

๑ British Dental Journal 2005; 198: 139-143 of the energy, and the patient is cured. The scientific model is based on 'The Gate Control Theory' where it has been shown that acupuncture releases neurotransmitters which act at the second layer of the dorsal horn that can effectively block any incoming pain transmission via the C-fibres, by releasing encephalin. ${ }^{3}$ Thus a clear distinction exists between traditional and western acupuncture, but the approaches overlap considerably. ${ }^{4}$ Both traditional and western acupuncturists identify acupuncture points by their location in the meridians. Among medically trained acupuncturists points for a particular treatment are selected with relevance to neurological and muscular anatomy. Vincent, ${ }^{5}$ examining the uses of acupuncture in western medicine, claims that the treatment may be effective whether or not the theory is valid. In a prospective study of over 55,000 treatments given by medical trained acupuncturists only 63 mostly minor adverse events - were identified. ${ }^{6}$ The amount of research on acupuncture conducted within branches of medicine has been vast leading to over 200 clinical trials. $^{7}$ More than 25 systematic reviews and meta-analyses have evaluated the clinical efficacy of acupuncture. ${ }^{8}$
Recently several practical and scientific training programmes in acupuncture have been conducted in the UK for dental practitioners through the auspices of the British Medical Acupuncture Society (BMAS), the British Dental Acupuncture Society (BDAS) or by accredited consultant acupuncturists. Seventy-three dental members are now registered with BDAS. The volume of published uses of acupuncture in dentistry is low. ${ }^{9}$

The aims of this study were to audit how the UK dentists who have undertaken scientific training have put their skills to clinical use, and to examine the common situations for which acupuncture therapy is used in providing dental care.

\section{THE AUDIT}

All acupuncture courses for dentists run in the 10 year period 1993-2002 were reviewed to establish their number, duration and registered participants. A register of trained dental acupuncturists is now maintained by the BDAS. As a part of training, all participants receive basic training in the 12 main meridians referred to in the Chinese acupuncture literature the local and distal acupuncture points 


\section{PRACTICE}

and trigger points that are of practical use in dentistry. The practical course outlines the methods of delivery, basic concepts of hygiene and indications and contraindications for its uses. The trainers encourage the participants who complete the training to use this complementary therapy as an adjunct in their clinical dental practice. Those who use the system are advised to submit returns to the BDAS when they have completed their first 10 cases on use of acupuncture in practice. This is to allow a dentist trained in acupuncture having attended the basic course, practical course and post basic course (approximately 40 hours training) to receive a diploma of basic competence. A standard proforma provided by the BDAS was used for auditing this information. This included the demography of the dentists reporting the uses, the conditions for which acupuncture is used in practice, the number of treatments offered per subject and the outcome semi-quantitatively assessed on $0-5$ scale ( $1=$ got worse, $2=$ no change, 3 =fair, $4=$ better, $5=$ =xcellent) graded by the patient. The submitted proformas were used in this audit to examine the situations in which practising dentists newly trained in acupuncture used this traditional method in daily practice and the reported outcome following therapy. As this was a simple audit of proformas institutional ethical approval was not sought.

\section{FINDINGS}

From 1993 to June 2002, to our knowledge 29 scientific training courses on acupuncture for dentists were conducted in the UK in locations in London and Sheffield. They were graded as basic $(n=14)$, post basic $(n=6)$, practical $(n=7)$, or advanced courses $(n=2)$ depending on the contents of each. Each of these levels is targeted at practitioners with varying experience and competence. Morever, three scientific meetings have also been held.

During this period altogether 225 registered UK dental practitioners have received such scientific training. Of the dentists who attended UK courses, 40 completed their training by reaching the post basic level of competence having attended all parts of training. These 40 trained dentists worked in different primary care settings. Demography of individual dentists providing acupuncture $(n=20)$ and those not practicing acupuncture $(n=20)$ is shown in Figure 1.

Over the period, 238 subjects received acupuncture treatment by the 20 dentists who completed competence proformas. Fourteen reports were rejected as they concerned treatments of no relevance to dentistry.
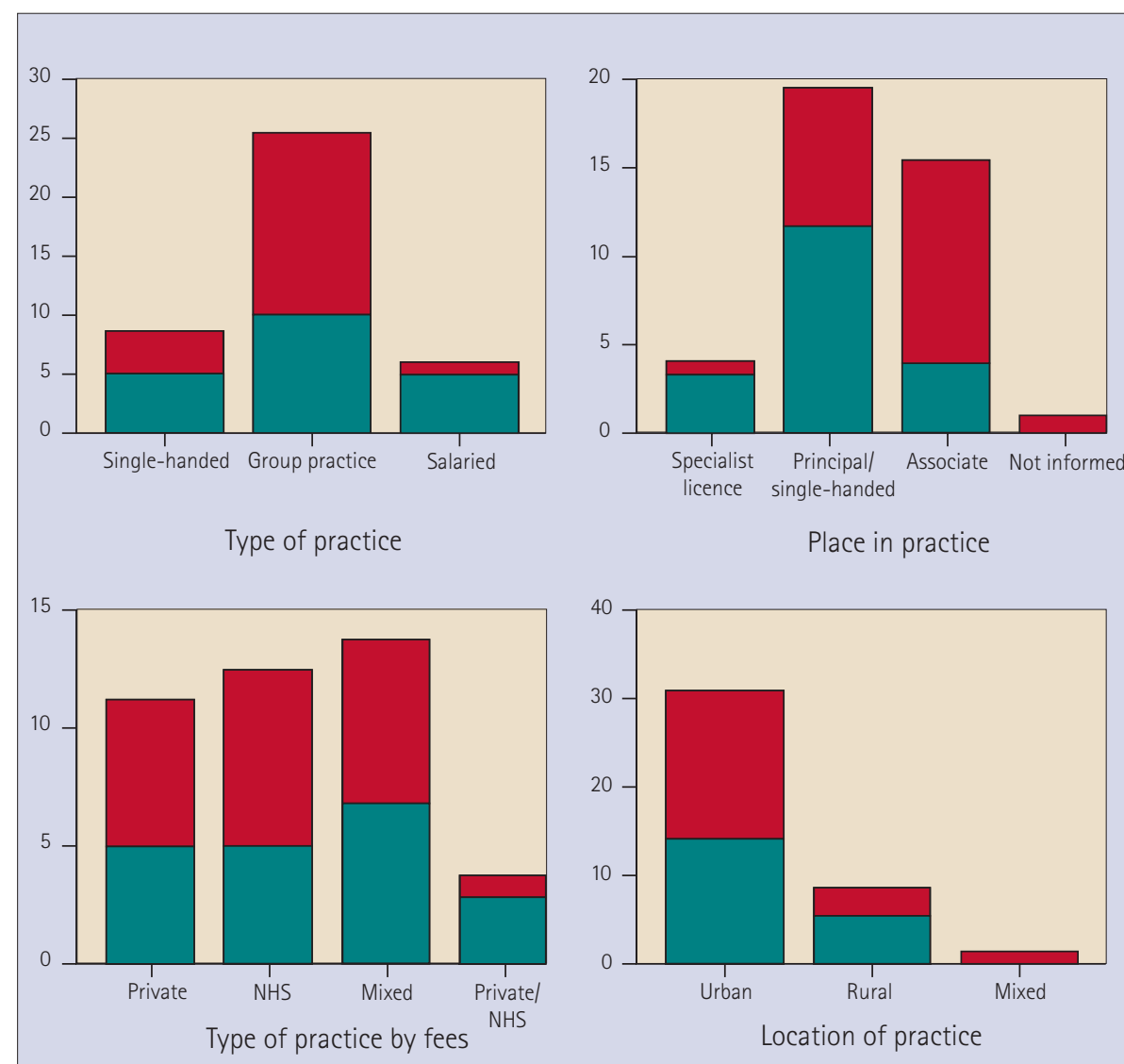

$\square$ Study group participants

$\square$ Non-participants

Fig. 1 Demographic data of dentists in the study $(n=20)$ compared with non-participants

Among 224 subjects who received acupuncture in dental practices 61 were male and 163 were female. Their ages ranged from 7 to 83 (mean 46) years. The conditions for which acupuncture treatment was used and the mean number of treatments offered are shown in Figure 2. None of the dentists surveyed used acupuncture for relief of dental pain or as an alternative for conventional analgesia during restorative treatment or exodontia. On average each patient received 2.6 treatments (range 1-5) for his or her complaint. The acupuncture points used by the practitioners are listed in Table 1. Of these, 30 were local points and three distal points. In addition, in 14 of the patients trigger points in addition to acupuncture points were used for therapy and in three cases, ear acupuncture was practised.

The outcome, reported subjectively by patients, was graded to give a mean score of 3.06 (no response 1 and excellent 5). None of the patients recorded 0 as an outcome suggesting that the condition being treated did not get worse. Few patients recorded no response to acupuncture in the categories of anxiety and in the pain group. No untoward effects were reported by any of the patients or were noticed by the practising dentist.

\section{POINTS OF INTEREST}

It is stated that to practise acupuncture a trainee requires extensive training up to two years at best. ${ }^{10}$ In the past 10 years several short training programmes have been conducted to teach acupuncture technique to UK dentists. The dentists receiving training attended a few courses on several weekends during which they learnt a small range of simple techniques. The present study suggests that following training about a half of the trained dentists use this technique in routine practice. Most completing the survey mainly used the technique in control of anxiety or directed at musculoskeletal and other chronic painful conditions and generally used it as an adjunctive treatment. The situations for which the technique was used are briefly discussed below.

\section{Anxiety and dental phobias}

Dentists in the present study used acupuncture most frequently for anxious patients receiving routine care. Fear of dental treatment constitutes one of the major obstacles to receiving dental treatment in western countries. There are several diagnostic categories of dental anxiety. ${ }^{11}$ In the UK $10 \%$ of people avoid dental treatment because of dental anxiety and 


\begin{tabular}{|c|c|c|c|c|c|c|c|c|}
\hline Points used & Anxiety & $\begin{array}{l}\text { Facial pain, } \\
\text { headache, } \\
\text { neck pain }\end{array}$ & Neuralgia & TMD & $\begin{array}{l}\text { Sinusitis } \\
\text { and } \\
\text { allergies }\end{array}$ & $\begin{array}{l}\text { Gagging } \\
\text { reflex }\end{array}$ & Xerostomia & Other \\
\hline \multicolumn{9}{|l|}{ Local points } \\
\hline LI-20 & 1 & & 2 & & 2 & & & \\
\hline ST-2 & & & 3 & & 6 & & & \\
\hline ST-3 & 1 & & 3 & & 1 & & & \\
\hline$\overline{S T-4}$ & & & 1 & & 1 & & 4 & \\
\hline ST-5 & 1 & 2 & & 9 & 1 & & 4 & 3 \\
\hline ST-6 & & 2 & & 11 & & & 5 & 3 \\
\hline ST-7 & 1 & 1 & & 13 & & & 5 & 1 \\
\hline \multicolumn{9}{|l|}{ ST-8 } \\
\hline $\mathrm{TE}-16$ & & & & 1 & & & & \\
\hline $\mathrm{TE}-17$ & & & & 1 & & & & \\
\hline$\overline{\mathrm{TE}-21}$ & & & & 4 & & & & \\
\hline SI-17 & & & & & & & & 1 \\
\hline SI-18 & & & & & & & & 1 \\
\hline SI-19 & 2 & 1 & 2 & 12 & 1 & & & 1 \\
\hline \multicolumn{9}{|l|}{ GB-8 } \\
\hline \multicolumn{9}{|l|}{ GB-14 } \\
\hline GB-20 & 1 & 17 & & 4 & 1 & & & \\
\hline$\overline{\mathrm{GB}-21}$ & & 16 & & 4 & & & & \\
\hline$\overline{B L-2}$ & & & & & 2 & & 1 & \\
\hline $\mathrm{BL}-10^{1} / 2$ & & 4 & & & & & & \\
\hline GV-14 & & 1 & & & & & & \\
\hline$\overline{G V-20}$ & 9 & 5 & & 5 & & & & 2 \\
\hline$\overline{C V}-24$ & & & 1 & & & 11 & 1 & 1 \\
\hline EX-1 & & 1 & & & 6 & & & \\
\hline EX-2 & 1 & 3 & & 2 & 1 & & & \\
\hline \multicolumn{9}{|l|}{ EX-3 } \\
\hline EX-6 & 7 & 2 & & 1 & & & & 1 \\
\hline New point & & & 2 & & 5 & & & \\
\hline \multicolumn{9}{|l|}{ Distant points } \\
\hline LI-4 & 18 & 6 & 1 & 7 & 4 & 3 & & 2 \\
\hline LI-11 & & & 1 & & & & & \\
\hline LR-3 & 1 & & & & & & & \\
\hline \multicolumn{9}{|c|}{ Other techniques } \\
\hline Trigger-points & 1 & 6 & & 6 & & & & 1 \\
\hline $\begin{array}{l}\text { Ear } \\
\text { acupuncture }\end{array}$ & 2 & & & & 1 & 6 & & 1 \\
\hline $\begin{array}{l}\text { scalp } \\
\text { acupuncture }\end{array}$ & & 1 & & & & & & \\
\hline $\begin{array}{l}\text { LI=large intestine } \\
\text { meridian, TE=trip } \\
\text { EX=extra points } \\
\text { Loal Points }=\text { point } \\
\text { Distant points }=p \\
\text { Ear points }=\text { acupu } \\
\text { Trigger points }=\text { w } \\
\text { TMD = temporom }\end{array}$ & $\begin{array}{l}\text { meridian, } \\
\text { le energiser } \\
\text { vhich locati } \\
\text { sl located in } \\
\text { oints locate } \\
\text { incture poir } \\
\text { ell describec } \\
\text { andibular d }\end{array}$ & $\begin{array}{l}\text { stomach meri } \\
\text { eridain, } G V=\text { go } \\
\text { s are generally } \\
\text { e face or neck } \\
\text { n remote body } \\
\text { located on the } \\
\text { ender points lo } \\
\text { unction }\end{array}$ & $\begin{array}{l}\text { dian, } \mathrm{Sl}=\mathrm{sm} \\
\text { vernor vesse } \\
\text { recognised } \\
\text { parts, e.g. th } \\
\text { ear } \\
\text { cated in mus }\end{array}$ & $\begin{array}{l}\text { intesti } \\
\text { neridia } \\
\text { hands } \\
\text { es on } t\end{array}$ & $\begin{array}{l}\text { eridian, } \mathrm{GB}= \\
\text { l=conceptio } \\
\text { ce or nexk }\end{array}$ & $\begin{array}{l}\text { All bladder } \\
\text { ressel meri }\end{array}$ & 更 & dder \\
\hline
\end{tabular}

fear ${ }^{12}$ and many studies worldwide report that about $10 \%$ of people are dentally phobic. ${ }^{13}$ For many anxious patients their only way of obtaining dental treatment is by way of sedation. Non-pharmacological techniques for management of dental anxiety need to be developed. Improvement of communication skills and behavioural management techniques have been highlighted as useful for this situation. ${ }^{14}$ Time constraints and reluctance of the practitioner to delve into behavioural therapy limits the use of these non-intrusive therapies. Acupuncture treatment of anxiety has been shown to be clinically effective. ${ }^{15}$ The role of acupuncture as an adjunct in the management of an anxious patient has not been widely explored in dental settings but has been substantiated in a single arm study. ${ }^{16}$ At present an audit on the subject is taking place within the members of BDAS.

In this survey, among 20 dentists who received training by attending short courses, 13 were using this skill in the manage- ment of an anxious patient. The majority of the dentists used needling points LI 4, GV 20 and Ex 6 for their delivery of acupuncture for these cases. These acupuncture points are scientifically valid for anxiety control and are based on sound clinical practice. The use of acupuncture to relieve dental anxiety may relate to neurophysiologic effects of the treatment through the release of acetylcholine and other endorphins. The survey suggests that dentists are able to develop this skill in the management of an anxious patient. The availability of this service in primary dental care settings to help anxious patients may reduce the referral of such cases to hospital sedation units for routine dental care. Acupuncture is a safe and relatively side-effect free method of treatment for anxiety and deserves careful study.

\section{Facial pain, headache and neck pain}

Richardson and Vincent ${ }^{17}$ reviewed the effectiveness of acupuncture for treatment of chronic pain. Both controlled and uncontrolled studies were included in this review. Headache was one of the most commonly researched pain conditions for which acupuncture was used. In this survey several dentists also attempted acupuncture for headache related symptoms. A variety of acupuncture points were used by the surveyed dentists for the treatment of headache. It appears some improvement of the condition was reported but this could be due a placebo effect. Placebo controlled trials are being designed by BDAS to further assess the feasibility of using dentists in providing care for these conditions.

A systematic review of 16 reported trials implied that acupuncture was effective in dental analgesia. ${ }^{18}$ None of the dentists surveyed here claimed they used the technique for any analgesic effect during a treatment procedure. Some dentists reported using facial points such as ST5 and ST7 in anxiety control. These acupuncture points are not recognised for anxiety, but may have been selected by an individual dentist for dental pain control rather than to relieve anxiety.

\section{Temporomandibular dysfunction (TMD)}

Substantial use of acupuncture therapy is reported in the treatment of patients with musculoskeletal disorders ${ }^{19}$ including facial muscular pain. ${ }^{20}$ Where conservative treatment such as the use of a bite raising appliance has failed, specialist clinics treating resistant temporomandibular joint pain have resorted to acupuncture therapy. ${ }^{21,22}$ Physicians and dentists have used this modality for treatment of TMD with lasting pain relief. $^{23}$ The National Institute of Health included myofacial pain in a Consensus Statement as a condition in 


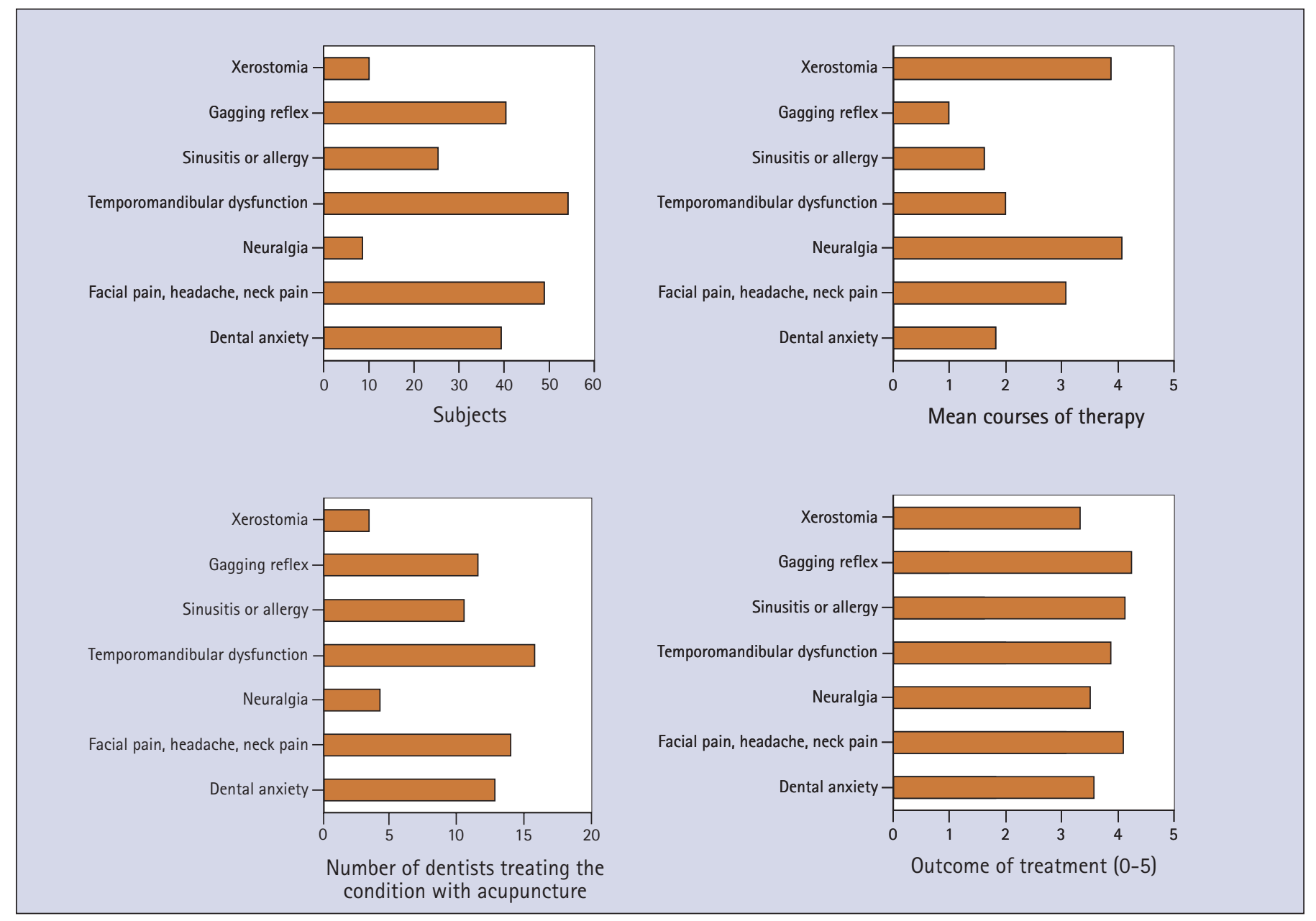

Fig. 2 The conditions for which acupuncture was used in dental practice. The number of subjects receiving therapy, mean courses of therapy, number of dentists using the the technique and mean outcome (0-5) are shown. For outcome ratings see text.

which promising results have emerged. ${ }^{24}$ Rosted $^{25}$ examined several clinical trials that used acupuncture therapy in the treatment of TMD and listed the points in and around the face for inserting the acupuncture needles. It was reassuring to note that the surveyed dentists used many of the recommended points: ST-7, SI19; but Ex-2 was used only by few. Table 1 shows the diversity of points used by dentists suggesting the need for further training in the selection of acupuncture points for effective treatment in TMD.

\section{Other conditions}

Several other clinical conditions were listed as being treated in dental practice. Surprising was the large number of dentists in the study treating sinusitis and allergies with acupuncture. The rationale for this is not clear but the objective appears to be pain relief. The dentist could also use this technique as a safety net to relieve sinusitis in order to clarify that the pain experienced was not dental in origin, thus avoiding over-treatment. A gagging reflex is encountered during dental procedures in some subjects and could influence patients' use of dental care. A recent study of ten cases illustrated that this reflex can be effectively controlled with acupuncture. ${ }^{26}$ All dentists in this survey reported encountering patients needing help to control their gagging reflex during dental procedures and all 20 dentists used CV-24 for this purpose as recommended in the literature. ${ }^{3}$ Most episodes of ear acupuncture (Table 1) were also directed towards patients with a gagging reflex. Potential uses of acupuncture in xerostomia ${ }^{27}$ are also being explored in dry mouth patients.

When used correctly acupuncture has been shown to be an extremely effective analgesic. $^{28,29}$ The first clinical investigation using acupuncture for dental anaesthesia was reported by Lee et al. ${ }^{30}$ Of the 20 cases included in their study 16 cases were deemed totally successful; seven cases were tooth extractions. A further use of acupuncture is as an alternative dental analgesia for individuals with a reported allergy to local anaesthetics. ${ }^{31}$ A standardised technique for dental acupuncture analgesia is presented by Brandwein and Corcos $^{32}$ who successfully completed over 2,000 dental procedures with acupuncture as the only form of anaesthesia. Future training programmes for dentists may benefit by adapting this scheme if acupuncture is to be used as a form of dental analgesia.

\section{Complications}

Traumatic lesions after acupuncture have been described in thoracic and abdominal viscera, in the peripheral and central nervous systems and in blood vessels. ${ }^{33}$ In this survey none of the dentists reported any complications to BDAS. Knowledge of normal anatomy is included in current training courses and regulatory bodies need to review safe practice. Most recorded complications occur in acupuncture carried out by people with a lack of medical/anatomical knowledge. ${ }^{9}$

\section{CONCLUSIONS}

A report from the House of Lords has highlighted that registered conventional health professionals should become more familiar with complementary medicine including acupuncture. ${ }^{34}$ Rosted $^{35}$ writing in the British Dental Journal claimed that a short training course can allow the technique of acupuncture to be an effective tool in every dentist's hands. We examined in this audit how such training courses in the UK 
have geared towards the needs of dentists wishing to practise acupuncture. Many completing the proforma appear to be using recommended needling points on a range of conditions that are amenable to treatment with acupuncture. From this preliminary survey we conclude that following standardised training and accreditation by a professional organisation, dentists interested in complementary medicine are able to provide this service to their patients. We would, however, caution that randomised controlled trials in dentistry are needed to evaluate acupuncture treatment as is currently being assessed in some areas of medical practice. ${ }^{36}$

1. Lewith G T, Hyland M, Gray S F. Attitudes to and use of complementary medicine among physicians in the United Kingdom. Complement Ther Med 2001:9: 167-172.

2. Rosted P, Joergensen VK R. The connection between serious side effects after acupuncture and the therapists' qualifications. Akupunktur 2000; 1 : 6-9.

3. Stux G, Pomeranz B. Acupuncture; Textbook and Atlas. Heidelberg: Springer Verlag, 1987.

4. Vickers A, Zollman C. ABC of complementary medicine. BrMed J 1999; 319: 973-976.

5. Vincent C A. Acupuncture as a treatment for chronic pain. In:Lewith G T, Aldridge D (Eds). Clinical Research Methodology for Complementary Therapies. pp289-308. Hodder and Stoughton: London, 1993.

6. Yamashita H, Tsukayama H, Tanno Y, Nishijo K. Adverse events related to acupuncture. J Am Med Assoc 1998: 280: 1563-1564.

7. Forman J. What the research shows. The Boston Globe 1995; 22: 25-7.
8. Kaptchuk T J. Acupuncture: theory, efficacy and practice. Ann Intern Med 2002; 136: 374-384.

9. Rosted P. The use of acupuncture in dentistry: a review of scientific validity of published papers. Oral Dis 1998; 4: 100-104.

10. Campbell A. Acupuncture requires extensive training to be practised at best. www.bmj.com, 3 Nov 1999

11. Locker D, Liddell A, Dempster L, Shapiro D. Age of onset of dental anxiety. J Dent Res 1999; 78 : 790-796.

12. Todd J E, Lader D. Adult dental health 1988 United Kingdom. London: HMSO, 1991

13. Freeman R. A psychodynamic theory for dental phobia. BrDent J 1998; 184: 170-172.

14. Freeman R. Assessing and managing dental phobia in general practice: some practical suggestions. Br Dent J1998; 184: 214-216.

15. Tao D J. Research on the reduction of anxiety and depression with acupuncture. Am J Acupuncture 1993; 21:327-9.

16. Sokol D J, Sokol S, Sokol C K. A review of nonintrusive therapies used to deal with anxiety and pain in the dental office. J Am Dent Assoc 1985; 110 : 217-222.

17. Richardson PH, Vincent C A. Acupuncture for the treatment of pain: a review of evaluative research. Pain 1986; 24: 15-40.

18. Ernst E, Pittler M H. The effectiveness of acupuncture in treating acute dental pain: a systematic review. $\mathrm{Br}$ Dent J 1998; 184: 443-447.

19. Chandola A, Young Y, McAlister J, Axford J S. Use of complementary therapies by patients attending musculoskeletal clinics. J Royal Soc Med 1999; 92 13-16.

20. Johansson A, Wenneberg B, Wagersten C, Haraldson T. Acupuncture in treatment of facial muscular pain. Acta Odontol Scand 1991; 49: 153-158.

21. List T, Helkimo M. Acupuncture in the treatment of patients with chronic facial pain and mandibular dysfunction. Swed Dent J 1987; 11: 83-92.

22. Ho V Bradley P. Acupuncture for resistant temporomandibular joint pain dysfunction syndrome. Acu Med 1992; 10:53-55
23. Corcos J, Brandwein A. Treatment of temporomandibular joint pain by acupuncture. Am J Acupuncture 1976: 4: 157-160.

24. NIH Consens Statement 1997. Acupuncture Nov 3-5, 1997.

25. Rosted P. Practical considerations for the use of acupuncture in the treatment of temporomandibular disorders based on the outcome of published controlled studies. Oral Dis 2001; 7: 109-115

26. Fiske J. The role of acupuncture in controlling gagging reflex using a review of ten cases. Br Dent J 2001; 190: 611-613.

27. Blom M, Dawidson I, Fernberg J-O, Johnson $G$, Anger-Mansson BA. Acupuncture treatment of patients with radiation-induced xerostomia. Eur $J$ Cancer (B) 1996; 32B: 182-190.

28. Taub H A, Beard M C, Eisenberg L, McCormick R K. Studies of acupuncture for operative dentistry. JAm DentAssoc 1977; 95: 555-561.

29. Taub H A, Mitchell J N, Stuber FE, Eisenberg L, Beard M C, McCormack R K. Analgesia for operative dentistry. A comparison of acupuncture and placebo. Oral Surg 1979; 48: 205-210.

30. Lee M H M, Teng P, Zaretsky H H, Rubin M. Acupuncture anaesthesia in dentistry. NYState Dental J 1973; 3: 299-301.

31. Gerschman J A, Wikstrom P O. The use of acupuncture as an alternative dental analgesic in an individual with multiple allergies. Swed Dent J 1984: 8: 225-230.

32. Brandwein $\mathrm{A}$, Corcos J. Acupuncture analgesia in dentistry. Am J Acupuncture 1975; 3: 241-247.

33. Peuker E T, White A, Ernst E, Pera F, Filler TJ. Traumatic complications of acupuncture: therapists need to know human anatomy. Arch Farm Med 1999; 8: 553-8.

34. Mills SY. The House of Lords report on complementary medicine: a summary. Complement Ther Med 2001; 9: 34-39.

35. Rosted P. Introduction to acupuncture in dentistry. $B$ Dent J 2000; 189: 136-140

36. David J, Townsend S, Sathanathan R, Kriss S, Dore S. The effect of acupuncture on patients with rheumatoid arthritis: a randomised, placebo-controlled cross-over study. Rheumatology 1999; 38: 864-869. 